\title{
Effects of inkjet printed toughener on delamination suppression in drilling of carbon fibre reinforced plastics (CFRPs)
}

\begin{abstract}
Carbon fiber reinforced plastics (CFRPs) depend on their excellent mechanical properties and lightweight benefits, have been widely used as the most primary or the bespoke structures for the aerospace, transportation and energy sectors. However, a main challenge to limit the composite application is the difficulty on machining and high risks with failure such as delamination during machining, for instance, drilling process. The delamination or burrs produced during the drilling of the CFRPs could significantly reduce the bearing capacity and shorten the service life of the designed component and result in the waste eventually. Although optimisation of tooling geometrical design and drilling operational parameters have been reported with improvement, the high cost of design such tooling or processing conditions have not completed resolved, which have been specifically designed and tested based on the various types of fibre and resin systems in the market for different application demands. In this work, an experimental research was developed to improve the delamination and burrs resistance in the drilling of the CFRP laminates by increasing the interfacial fracture toughness using inkjet printing technology. Specifically, poly(methyl methacrylate) (PMMA) solutions with different concentrations were selected to print at the interface of the carbon fibre prepreg where the holes located, and co-cured together with layups to improve their interlaminar fracture toughness. The parametric study by printing various weight fraction contents of PMMA were experimentally performed to optimise and assess the toughening efficiency on the delamination and burrs resistance for drilling process, as well as the consideration of various feed rates effect. It was found that the inkjet printed mciro-PMMA at the interfaces of the CFRPs could effectively suppress the delamination and burrs around the hole. The optimal content of the PMMA solution was $10 \mathrm{wt}$ \% to offer the least damages, in particular, for the situation under the highest feed rate condition. The results of this study is significantly contribute a novel approach on locally toughening the composite interfaces to improve the drilling quality, which is specifically helpful to strengthen the joint property for the structural design stage for the aircraft.
\end{abstract}

\section{Introduction}

Lightweight and excellent mechanical strength of the components are always the priority during the design and processing and manufacturing stage of the aerospace, transportation, and energy fields. Carbon fiber reinforced plastics (CFRPs) that consist 
of carbon fibers and matrix epoxy resin sytem have been the ideal candidate to meet such criteria with high specific strength and modulus, abrasion and damage resistances etc. therefore, widely used as the primary structures with remarkable benefits offered [1-5]. However, it was also identified that a challenge to constrain the expansion of CFRPs application could be their relatively high cost of machining, in particular, drilling process which is highly demanded for assembly purpose by bolts. For instance, there are approximately three million holes required to be drilled for fastening in a large transport aircraft [6-8]. These holes are under strict quality control to ensure the safe and reliable performance due to any potential damages resulted from drilling process might significantly affect their service time and safety.

The different mechanical properties of the individual phases in CFRPs often result in difficulties to achieve a balanced cutting performance with ideal quality. This could be specifically reflected that the fiber with higher strength is always more difficult to cut than the matrix where the angled layups of CFRPs could have been subjected to a high risk with delamination around the hole due to the anisotropic features and the mismatch of the neighboured plies with different fibre orientations [3, 9, 10]. In addition, the far differences on the strengths between the carbon fibers matrix resins during the drilling could bring a debonding at the interface between them and form the burrs then. Therefore, serious damages with initiation and propagation of delamination and burrs around the drilled hole would become a critical concern to affect the eventual service quality and reliability for assembly[2,11]. The delamination could not only degrade the structural integrity, but also seriously reduce their bearing capacity to fail the joining. It would also decrease the surface quality of the processed workpieces so that cause the assembly error, resulting in the composite wastes [12-14]. Optimisation of the drilling process for CFRPs have been hence become one of the research hotspots in recent years.

A number of researches were reported to improve the drilling quality on composite by the optimised design of the tooling such as drill bit. Alternatively, processing parametric studies on the drilling operational conditions were investigated by experiments. For instance, Hocheng and Tsao et al. [15-17] developed the analytical model for delamination analysis during the CFRP drilling by the various designs of twist drill, candle stick drill, saw drill and core drill bits. It was indicated that the drill bits could play an determinant factor on the onset of delamination based on the different thrust force applied. A Taguchi method was employed for optimisation with the analysis of variance (ANOVA) concluded that all drill bits except twist design were usually easier to cause a small delamination initiation. Isbilir et al. [18, 19] studied the effect of stage ratios of step drill on delamination via the finite element (FE) simulation. The step drill has demonstrated an obvious suppression of the delamination form and growth compared to the general twist drilling, and the delamination factor decreased with the increasing of the stage ratio. Based on a comprehensive analysis of the effects 
of action point and cutting direction on material removal at the hole exit, Jia et al. [20] proposed a novel intermittent-sawtooth drill design on the one-shot drill. With the help of this specific drill bit, the cutting conditions at the hole exit were totally improved with a significant control on the reduction of the delamination after drilling. Durão and Marques et al. [21, 22] also compared a variety of drill point geometries in terms of delamination and concluded that the combination of control of the drill bit geometry with processing parameters could promote the reduction of delamination. For the processing parameters, Davim et al. [23] revealed the influences of cutting velocity and feed rate on delamination factors at the hole entrance and exit by Taguchi optimisation where the correlations between drilling parameters and delamination factors by multiple linear regression was explored. Tsao et al. [24] evaluated the cutting velocity ratio and feed rates on delamination by compound core-special drills through proposing a mathematical model with response surface methodology. The results indicated that the feed rate had demonstrated to be dominant to decide the delamination occurred under the drilling process. Feito et al. [25] also developed a numerical model to predict the CFRP drilling with the effects of feed rates and spindle speed on the delamination. Shahrajabian et al. [26] conducted a series of drilling experiments to clarify the feed rates and the spindle speed could be the crucial factors to determine the delamination formed. However, either way above had to experience a high number of manufacturing and experimental consumables, which also strongly depended on the material systems used.

Therefore, some researchers focused on the improvement through the material design []. As reported, , the inorganic whiskers or carbon nanofiber/nanotube applied at the interfaces of laminate have significantly improved the interlaminar fracture toughness. . Odagiri et al. [27] developed a kind of high-toughness prepreg based on the particulate interlayer toughening technology, aiming for an enhanced delamination resistance. Hojo and Matsuda et al. [28, 29] tested the fracture toughness of the interlayer-toughed CFRPs under mode I and mode II loading and concluded that adding thermoplastic polyamide particles at the interlayer zone of the CFRPs greatly improved the fracture toughness of the components. Sato et al. [30] also confirmed that the fracture toughness of CFRPs could be toughened by polyamide-12 (PA12) particles with more than twice higher than that of non-toughened CFRPs. Wang et al. [31] dispersed SiC whiskers along the interfaces of composite to improve the interlaminar fracture toughness of laminates, whicha both $\mathrm{G}_{\mathrm{IC}}$ and $\mathrm{G}_{\mathrm{IIC}}$ exhibited a nearly $50 \%$ and $25 \%$ increasing compared with those without whiskers. In addition, Arai et al. [32] inserted carbon nanofibers between the CFRP prepreg sheets to toughen CFRP laminates, and both GIc and GIIc of interleaved CFRP laminates were increased by 0.5 and 2 to 3 times, respectively, compared to the unmodified CFRP laminates. Similarly, Hamer et al. [33] found an toughening effect by the electrospun Nylon 66 nanofibrilmat on the fracture toughness of the composite under pure Mode I test and concluded a 
three-fold improvement in $\mathrm{G}_{\mathrm{Ic}}$ values compared to a non-interleaved carbon/epoxy laminate. Magniez et al. [34] upgraded the $\mathrm{G}_{\text {Ic }}$ and $\mathrm{G}_{\text {IIc }}$ of CFRPs up to $150 \%$ and $300 \%$ of their original values by incorporating electrospun poly(hydroxyether of bisphenol A) (phenoxy) nanofibrous. Liu [35] and White [36] et al. proposed both PA microparticles and carbon nanotubes together to toughen CFRP laminates where a remarkable increase of the Gic and Girc values was obtained with 1.3 and 2.5 times higher. However, the modification of material interfacial behaviour was mostly focused by the static mechanical tests with individual damage mode assessed where the severity of improvement on a dynamic machining process with mixed-mode effects was rarely studied.

In this work, the main objective is to study the improvement of delamination resistance during the dynamic drilling process for the CFRP laminates, with consideration of toughening mixed-mode damages. To avoid any change of the material design with a higher manufacturing efficiency, the local thermoplastic resin particles poly(methyl methacrylate) (PMMA) as the toughener were inkjet printed at the surface of the original prepregs where planned to be drilled, prior to lay-up and curing stage. A parametric study of the inkject printing optimisation with various PMMA contents was experimentally measured and assessed to analyse the improvement of damage resistance during drilling with the different feed rates. The mechanisms of delamination form and optimisation with the proposed toughening effects were concluded by guiding the higher drilling quality for multi-holes onto one integrated composite plate.

\section{Materials preparation and Experiments}

\subsection{Materials preparation}

\subsubsection{Strategies for toughening composite with improved damage resistance}

Based on the theory of Ho-Cheng et al.[37], delamination has been recognised as the predominant damage mode to affect the quality of drilled hole. That is because the drill bit would penetrate the composite at the end of the drilling, however, delaminations were the only damage modes to be still remained around the hole after drilling. The form of delamination was strongly dependent on the loads applied by the drill bits, as well as the inherent interfacial properties of the composites, which the interfacial strengths determined the initiation and fracture toughness then decided the propagation of delamination. Since the beginning of the drilling, the delamination was usually initiated at the first interface neighboured to the top ply for the relatively thick laminate, but occurred at the interface between last layers at the bottom when the thickness is thin. With the further feed of the drill bit, the initiated delamination kept propagating at the same interface, but also delaminations at other interfaces were driven to form simultaneously. Due to the initial delamination has degraded their mechanical 
properties, the drilling loads would accelerate the propagation of delaminations along other interfaces of the rest laminates. That is why at the end of the drilling delamination was always difficult to control and appearing around the drilled hope as the unexpected failure.,

Therefore, this research attempted to toughen the interfacial properties (strengths and fracture toughness) of laminate so that improve the delamination resistance during drilling. Compared to the traditional manual deposition with the drawback of the uneven distribution of additives, , the inject printing technology was adopted for a better quality of deposition and accurate control of the micro-particles contents distributed onto the raw prepregs. It is thus helpful to perform a parametric study to pursue the optimised interfacial toughening by the optimal deposition contents with personalised droplet patterns printed.

\subsubsection{Material selection}

The unidirectional carbon fibre prepreg (XPREG® XC130) used in this work was produced by Easy Composites Ltd, UK. The prepreg is approximately $0.25 \mathrm{~mm}$ thick and $300 \mathrm{~mm}$ wide, which is designed to be oven cured with typical curing cycle suggests offered by manufacturer [39]..

In addition, PMMA (Sigma Aldrich, UK) was selected as the toughening material for inkjet printing. The reason to print PMMA is it has been proven to be an effective functional micro-particles for toughening the interfacial properties of laminate. In particular, it was an ideal candidate to be co-cured with prepregs at the oven curing cycles[40]. In order to achieve a high printing quality, the PMMA dispersed within the organic solvent N,N-Dimethylformamide (DMF) has been identified to enable an optimal viscosity for inkjet printing. Moreover, the DMF offers a perfect evaporation rate matches with the printing process, which avoids excessive solvent on the prepreg or the print head clogging [40]. To find out the optimal concentration of PMMA solution on delamination resistance during drilling, the $5 \mathrm{wt} . \%, 10 \mathrm{wt}$. \% and $20 \mathrm{wt}$. \% PMMA solutions were formulated, respectively, and drilled under the various feed rates.

\subsection{Fabrication of toughened composite by inkjet printing}

The carbon fibre composite was laid up with the stacking sequences of [(0/90) 2]s, which is $90 \mathrm{~mm}$ long, $70 \mathrm{~mm}$ in width and $2 \mathrm{~mm}$ thick (See Fig. 1a). This dimension of laminate was selected to fit in the fixture of drilling operations as shown in Fig. 2.

The Dimatix DMP-2850 (Fujifilm Ltd, US) in Chester Smart Composite Group (CSCG) was used for inkjet printing PMMA particles. An embedded online inkjet observation system can real time monitor the printing process so that helps to calibrate and adjust the proper printing parameters at the pre-print phase. The nozzles 
consist of the piezoelectric ceramic crystals to ensure the linearity of the ink and guarantee a reliable accuracy when the printing is repeatedly operated. The vacuum supplied by the platform of the printer helps to strictly fix the substrate during printing. As the purpose to improve the local interfacial properties for drilling, there were only three circular areas selected for printing with a diameter of $12 \mathrm{~mm}$ where the composite workpiece was supposed to be drilled (See Fig. 1b). Such proposed toughened areas were printed onto individual prepreg plies prior to layup, as shown by Fig. 1c.

The printed prepreg was then laid up as the designed layup and cured within the OV301 oven with reference of the advised curing cycles (Table 1). The laminates with three various PMMA contents as well as neat CFRP without any printed particles were manufactured for drilling tests.

Table 1 Curing cycles used for the curing of the CFRP laminates

\begin{tabular}{cccccc}
\hline Cycle & 1 & 2 & 3 & 4 & 5 \\
\hline $\begin{array}{c}\text { Temperature } \\
\text { change speed } \\
\begin{array}{c}\text { Temperature at the } \\
\text { end of the cycle } \\
\text { Spend time }\end{array}\end{array}$ & $+10^{\circ} \mathrm{C} / \mathrm{min}$ & 0 & $+2^{\circ} \mathrm{C} / \mathrm{min}$ & 0 & $-1^{\circ} \mathrm{C} / \mathrm{min}$ \\
\hline
\end{tabular}
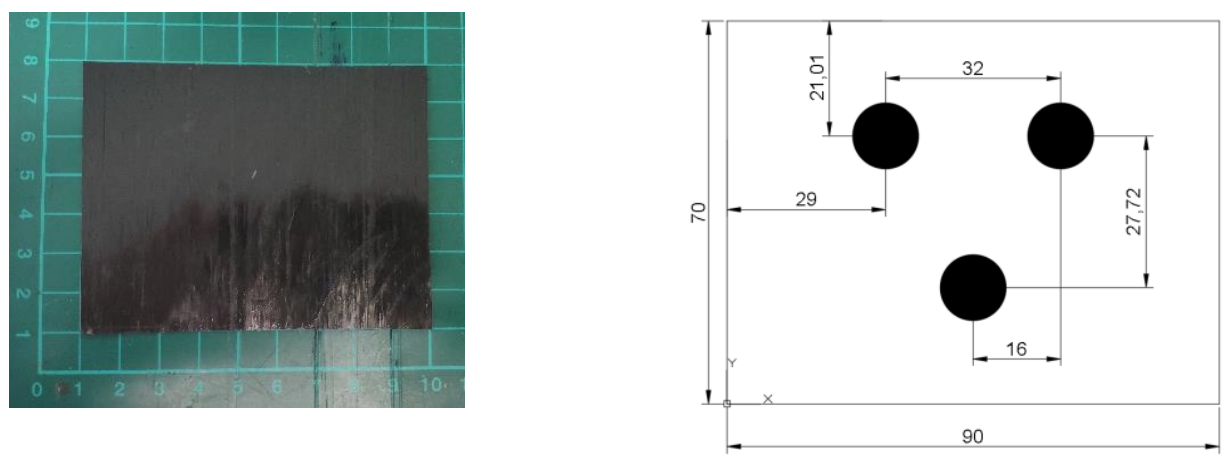

1a. Prepreg preparation

1b Inkjet printing designed pattern

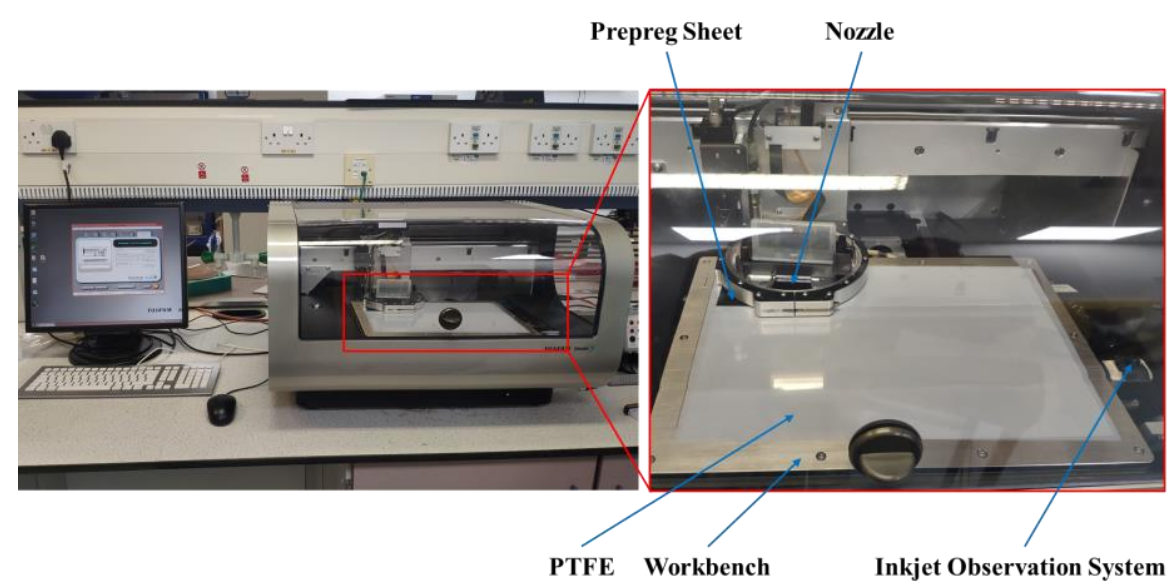

c. Schematic of inkjet pinting 
Fig. 1 Material preparation with inkjet printing setup

\subsection{Drilling experiment setups}

Drilling experiments for the toughened CFRP laminates were carried out by the Micron 3-axis machining centre, which was powered with maximum $13 \mathrm{~kW}$. A schematic of drilling setups can be illustrated by Fig. 2 where the Kistler 9253B dynamometer is responsible to measure the thrust force during drilling. To meet a standard drilling request, a fixture with a number of holes with diameter of $14 \mathrm{~mm}$ was used to clamp the composite workpiece to ensure a satisfied quality of the drilling. . The Kistler 5080 amplifier and 5697A data acquisition play the important roles to record the force data, which a sampling frequency of $24 \mathrm{kHz}$ was used for the whole drilling tests in this work. A KEYENCE VH-Z50L microscope helped to observe and record the induced delamination around the hole after drilling.

In order to offer a comparable data used for analysis of the inkjet printed particles, a uniform design of the twist drill bit was used in this work. The drilling tool is made from YG8 cemented carbide with polycrystalline diamond coatings externally to improve the wear resistance of the bit during drilling. Based on previous literature reviews, the feed rating has been a critical factor to determine the delamination produced by drilling composite, therefore, three most widely used feed rates were performed in this work to find out the proposed micor-particles toughening effects onto different drilling operational conditions. Details of the twist drill and drilling conditions are listed in Table 2.

Table 2 Details of the twist drill and drilling conditions

\begin{tabular}{cccccc}
\hline & Drill bit & & \multicolumn{3}{c}{ Drilling conditions } \\
Diameter & $\begin{array}{c}\text { Point angle } \\
(\mathrm{mm})\end{array}$ & $\begin{array}{c}\text { Helix angle } \\
\left(^{\circ}\right)\end{array}$ & $\begin{array}{c}\text { Spindle } \\
\left(^{\circ}\right)\end{array}$ & $\begin{array}{c}\text { Feed rate } \\
\text { speed }(\mathrm{rpm})\end{array}$ & $\begin{array}{c}\text { Coolant } \\
(\mathrm{mm} / \mathrm{min})\end{array}$ \\
\hline \multirow{2}{*}{8} & & & & 150 & \\
& 90 & 34 & 3000 & 350 & None \\
& & & & 550 & \\
\hline
\end{tabular}

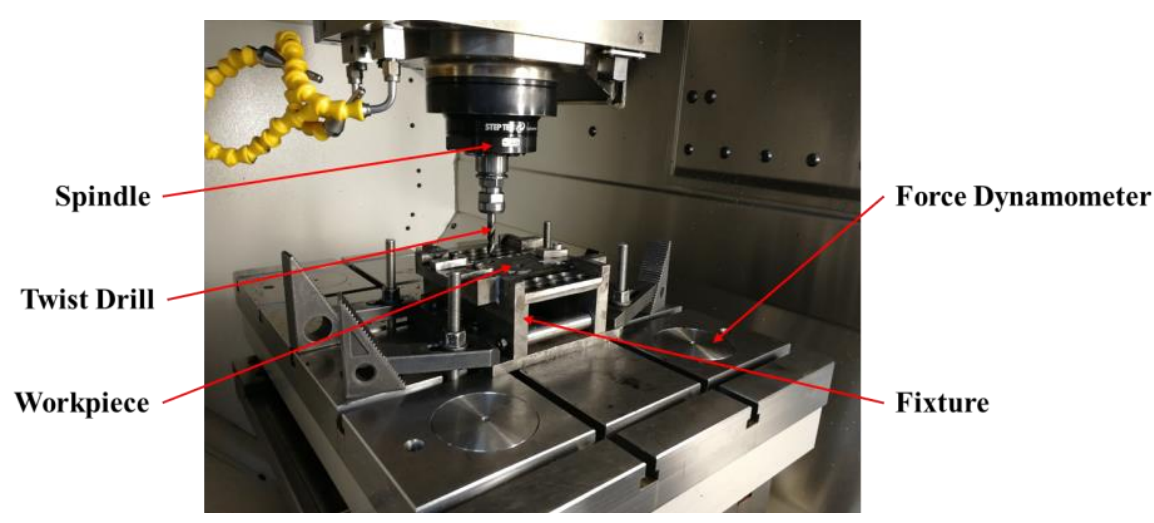

Fig. 2 Setup of the drilling experiment 


\section{Results and discussions}

CFRP laminates toughened by several weight contents of PMMA solutions were manufactured and experimentally drilled at the different feed rates. The thrust force, torque and drilling induced damages by evaluating the laminates with and without micro-particles printed were discussed, respectively, for demonstrating the toughening effects and the mechanisms of improving the damage resistance by the proposed method in this work.

\subsection{Drilling damages assessment}

As the primary damage modes could be visually observed around the hole after drilling, the KEYENCE microscope was used to assess and analyse the damage resistance resulted from the printed PMMA micro-particles. Although slight damage was seen at the entrance, the exit was where the delamination were mostly found, . therefore, the hole exit was focused in the analyses of damages.

Figure 5 shows the typical damages formed at a drilled hole exit of the laminate with $5 \%$ wt of PMMA printed for toughening. In order to quantitatively assess the effect of the tougheners in different concentrations with the feed rates, a damage factor was defined:

$$
F_{D A M}=\frac{A_{D A M}}{A_{H O L}}
$$

Where, $A_{D A M}$ is the area of the damage at the hole exit, and $A_{H O L}$ is the area of the hole. To accurately identify the damaged area, $A_{D A M}$, in this work an algorithm was emplyed $[18,19,41,42]$ to extract the individual damaged areas together to compute the damage factor. The Matlab programme was developed to postprocess the digital image analysis under three steps: 1) filtering the dynamic noise for improved quality; 2). identifying the individual damage areas by the edge detection; 3)extracting the total damaged area, as listed in the Table 5. Therefore, the damaged area could be accurately obtained based on the number of the black pixels, NDAM, with the length LSCA and pixel numbers $\mathrm{N}_{\mathrm{SCA}}$ referring to the scale defined for the image, by Eq. 2.

$$
A_{D A M}=N_{D A M}\left(\frac{L_{S C A}}{N_{S C A}}\right)^{2}
$$




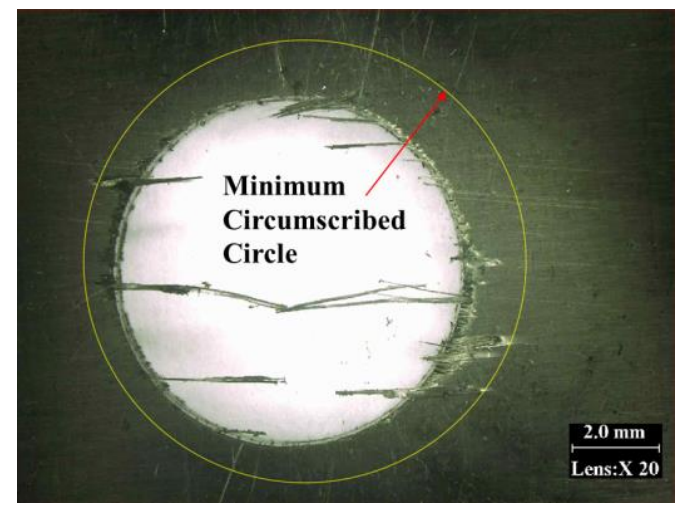

Fig. 3 A typical damage schematic of drilled composite (5 wt. \% PMMA solution, 550 $\mathrm{mm} / \mathrm{min}$ Feed rate)

To accurately capture the delamination at the exit of the hole, the damage factor was predicted by the area of the debonding, $A_{D A M}$, with the pixel number of the black area, $N_{D A M}$, where the Eq.3 was obtained by substituting Eq. 2 into Eq. 1,.

$$
F_{D A M}=\frac{A_{D A M}}{A_{H O L}}=\frac{N_{D A M}\left(\frac{L_{S C A}}{N_{S C A}}\right)^{2}}{A_{H O L}}
$$

Table 6 Damage at the hole exit

\begin{tabular}{|c|c|c|c|c|}
\hline $\begin{array}{l}\text { Feed rate } \\
(\mathrm{mm} / \mathrm{min})\end{array}$ & $\begin{array}{c}0 \text { wt. } \% \text { PMMA } \\
\text { solution }\end{array}$ & $\begin{array}{c}5 \text { wt. } \% \text { PMMA } \\
\text { solution }\end{array}$ & $\begin{array}{c}10 \text { wt. } \% \\
\text { PMMA solution }\end{array}$ & $\begin{array}{c}20 \text { wt. } \% \\
\text { PMMA solution }\end{array}$ \\
\hline 150 & & & & \\
\hline 350 & & & & \\
\hline 550 & & & & \\
\hline
\end{tabular}




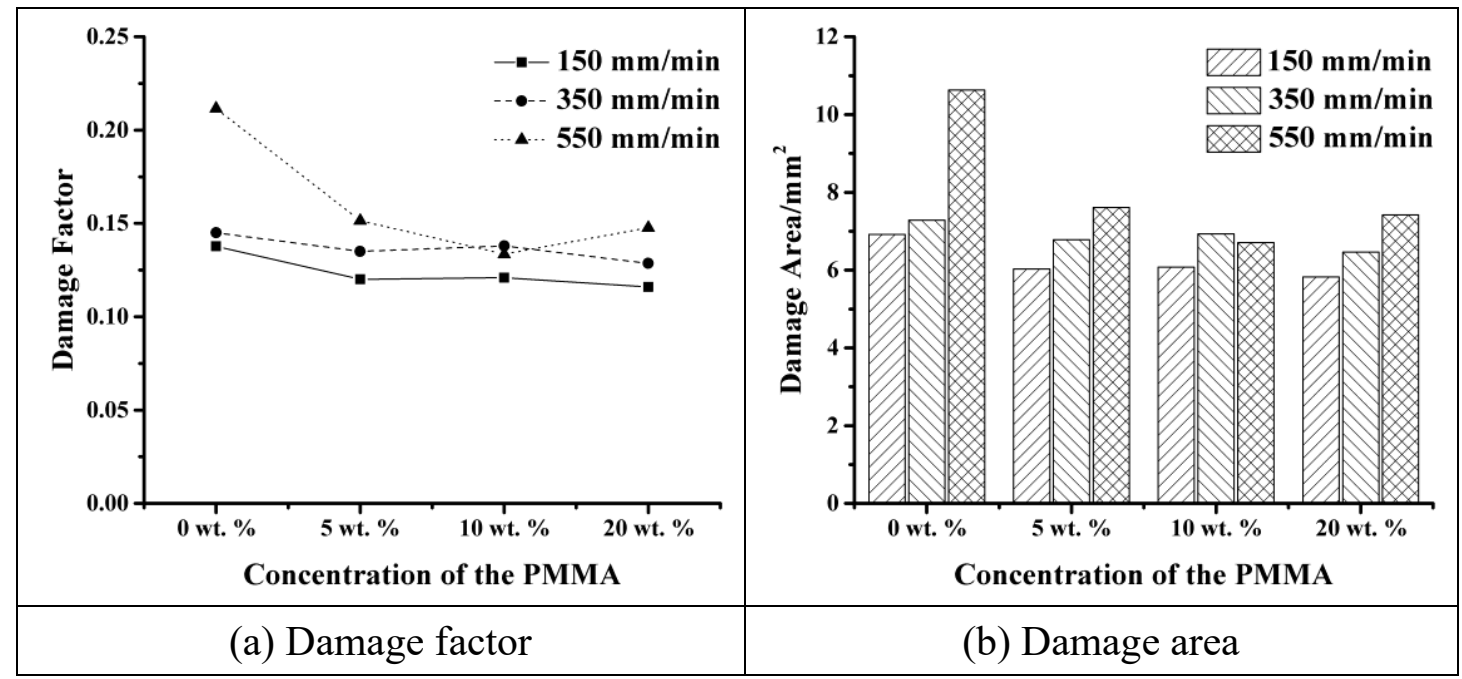

Fig. 7 Change of the damage at the hole exit with the toughener contents and feed rates

The damage factors measured under the various feed rate for laminates with and without toughening were compared in Fig. 7. It can be seen that the whole toughened laminates exhibited a smaller damage factor than neat CFRP which indicated the inkjet printed PMMA at interfaces have significantly contributed towards an enhancement on damage resistance. However, three individual contents of toughened laminates by PMMA demonstrated the different tendency on the damage resistance under the various feed rates.

For drilling by a low feed rate of $150 \mathrm{~mm} / \mathrm{min}$, the different toughner contents seems not to be a key factor to improve the delamination resistance (see Fig. 7a). This gave the confidence that the proposed method by inkjet printing PMMA could improve the drilling quality with obvious reduction of damages, however, there is no need to print a high concentration of tougheners at such less intensive drilling, avoiding an unnecessary cost and time consuming resulted.

As expected, the delamination areas were obviously enlarged with the increased feed rates, as shown by Fig. 7b. For the drilling when the feed rate reached $350 \mathrm{~mm} / \mathrm{min}$, the toughening effect tent to be stable since $5 \mathrm{wt} \%$ while the optimal damage resistance was achieved at $10 \mathrm{wt} \%$ of PMMA toughers printed at the highest feed rate of 550 $\mathrm{mm} / \mathrm{min}$. It indicated that a $10 \mathrm{wt} \%$ concentration of PMMA toughners was advised to be optimal with fewest damages formed for the intensive drillings (feed rate $>350 \mathrm{~mm} / \mathrm{min}$ ).

The damage areas above were analysed through a straightforward approach to measure the delamination at the exit of hole. Considering the potential overall damaged areas where were failed to observed or ignored, a different strategy by defining the minimum circumscribed circle [43], $A_{D E L}$, was performed to further find out the toughening 
effect by the proposed method, as shown by Fig. 8 . The delamination factors were then calculated by Eq 4:

$$
F_{D E L}=\frac{A_{D E L}-A_{H O L}}{A_{H O L}}
$$

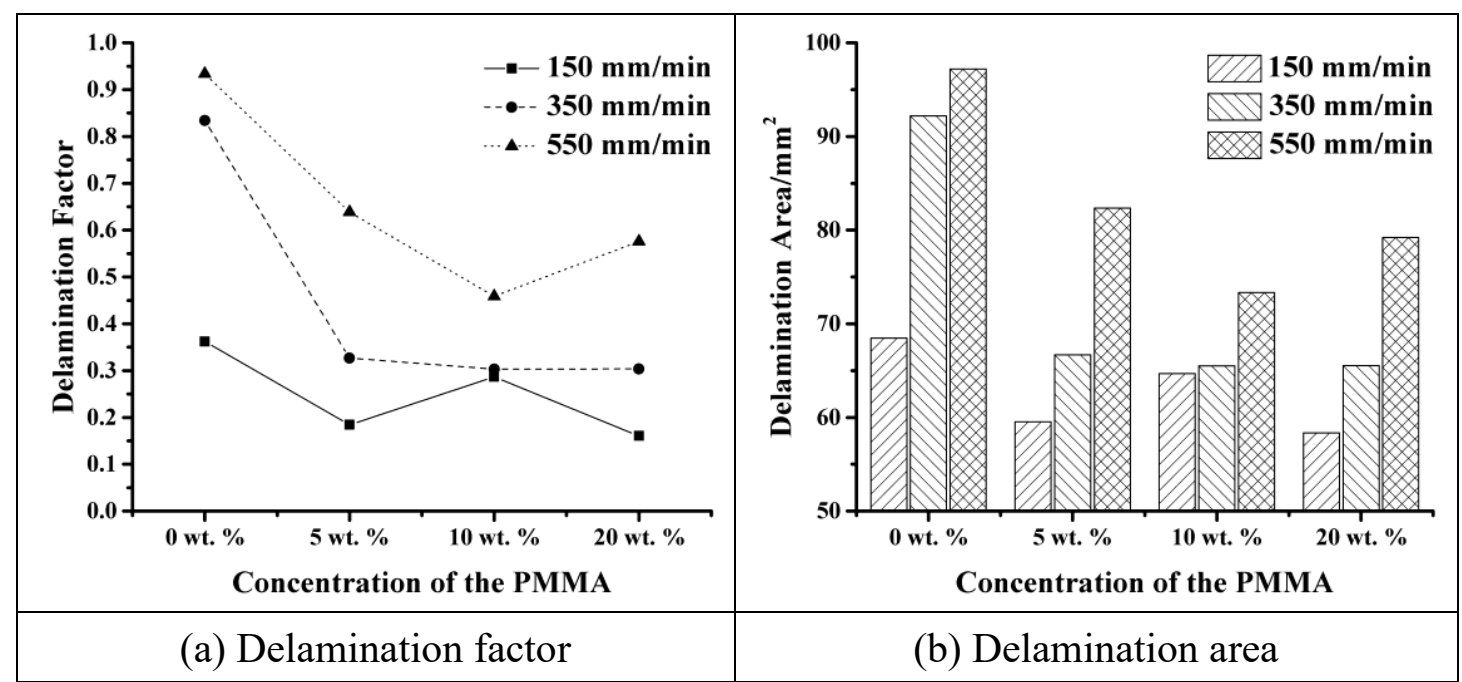

Fig. 8 Change of the delamination with the toughener contents and feed rates

The calculated delamination area and delamination factors are shown in Figs. 8.

The delamination factor shown in Fig. 8a has demonstrated an agreement with what was shown in Fig. 7, which the damage resistance of the laminates with toughening have been significantly improved. For lower feed rate of $150 \mathrm{~mm} / \mathrm{min}$, almost same damage areas (See Fig. 8b) were created for both 5 and $20 \mathrm{wt} \%$ toughened laminate whereas a larger damage area was resulted by the $10 \mathrm{wt} \%$ toughners printed. The difference of the damaged areas might be due to the assumption of the calculation from the circular areas captured. But the result helped to further prove the earlier finding that a low weight content of toughener would be recommended during drilling when feed rate was low.

For the higher feed rates scenarios, an optimal weight content of $10 \%$ of the toughened PMMA was found to decelerate the most delamination propagations during drilling where showed the smallest damage area and factor, in particular, at a more intensive feed rate level. Compared to the results in Fig. 7, a good agreement has been met that both prediction approaches led to the same optimal content value of $10 \mathrm{wt} \%$ for the best toughening effect. It makes sense that with a higher PMMA content printed than $5 \mathrm{wt} \%$, the interfacial properties were further toughened and therefore the delaminations were kept decreasing. However, once the content value was beyond $10 \mathrm{wt} \%$, there might be excessive micro-particles deposited along the individual interface, which induced the local stress concentration and accelerated to initiate the delamination. Therefore, for high feed rate drilling request, $10 \% \mathrm{wt} \%$ was suggested to be optimal by minimisation of the delamination. 


\subsection{Toughening mechanism analyses}

According to the conclusions assessed in the section above, the least delamination was recorded when the toughener concentration was $10 \mathrm{wt}$. \%. Therefore, this typical case was selected to analyse the thrust forces and torques under different feed rates and compared with CFRP without printed PMMA, aiming to secure the toughening mechanism on how to minimise the delamination formed during drilling.

\subsubsection{Thrust force}

Figure 10 illustrates the thrust force histories by comparing both toughened and untoughened CFRPs at different feed rates of drilling. To get rid of the noise confusion from the measured data, a post-processing was conducted by developing a programme to filter the high frequency vibrations of those above $10 \mathrm{~Hz}$.

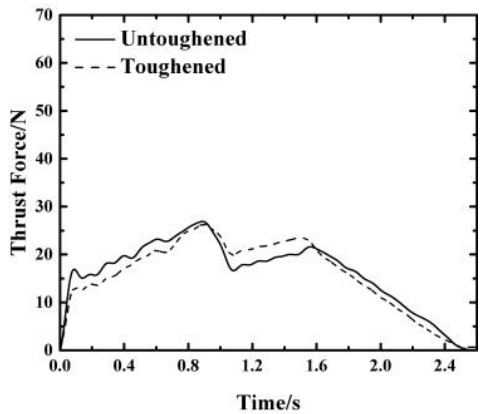

(a) $150 \mathrm{~mm} / \mathrm{min}$

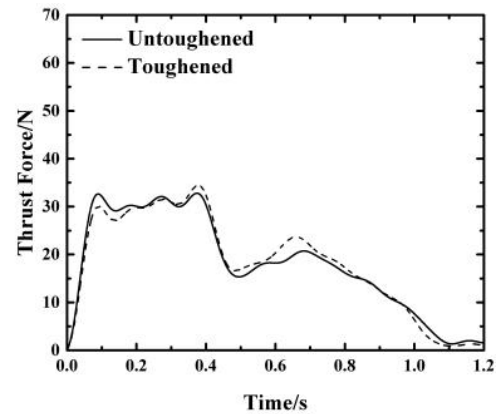

(b) $350 \mathrm{~mm} / \mathrm{min}$

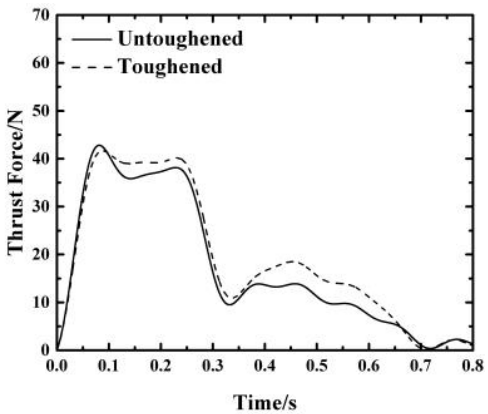

(c) $550 \mathrm{~mm} / \mathrm{min}$

Fig. 10 Thrust force histories of drilling untoughened and toughened by $10 \mathrm{wt}$ \% concentration PMMA CFRPs under different feed rates

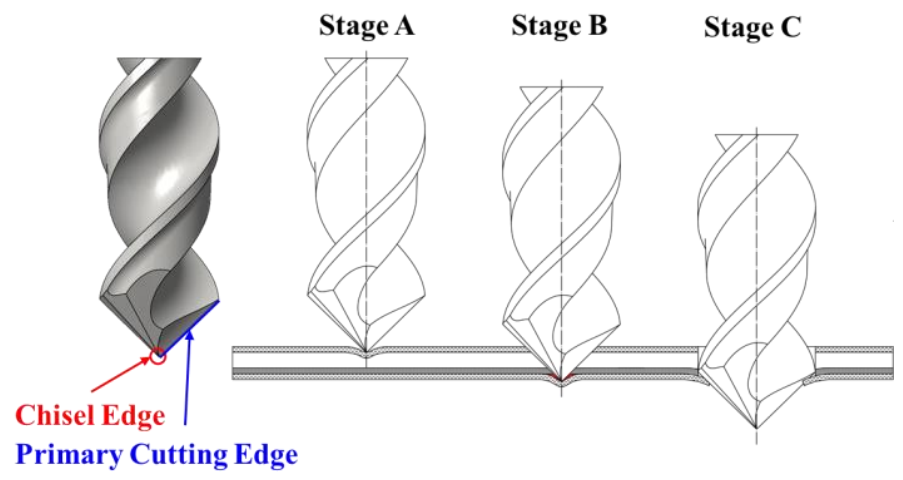

Fig. 11 Drilling process of the twist drill

It is hardly seen with an obvious difference at the initial drilling phase between laminates with and without toughening for all feed rates, however, with the drill bit further penetrated the laminates, the toughening was shown with a higher thrust force until complete drilling exit, especially at the highest feed rate condition. Therefore, in 
order to figure out the toughening mechanisms during the whole drilling process, three stages were categorised as A, B and C (shown in Fig. 11) to help clarify how the toughening affected delamination and reflected by the thrust forces in Fig. 10. In Stage A, it showed the moment that the chisel edge initially contacted the top surface and drilled laminate. . Stage B was the occasion that the chisel edge was at a critical status of the perforaion. . Following that, in Stage C, it was the scenario when drill bit has completely perforated the laminte. In stage A, the thrust force intensively increased since the feed of the drill bit started. The peak-to-peak oscillations could be observed afterwards because of the damage propagation with the drilling process. The thrust force obtained of the toughened laminate was smaller than that of the untoughened one at this phase. The reason might be due to the chisel edge was the only contributor to initiation of penetrating laminate, A toughened laminate offered a stronger bending resistance so that the penetration was initiated by in-plane damages of the top surfaces where the local stress was concentrated contacted with the drill bit.

At stage B, due to the drill bit has critically perforated the laminate, the chisel edge was less able to result a high reaction force from the contact of laminate like Phase A, the thrust force was hence significantly dropped. It has to be noted that the thrust force measured in the toughened laminate kept a larger value than that in the untoughened case. That could be attributed in the predominant role of the primary cutting edge, which determined the thrust force instead of the chisel edge. The toughened interfaces resulted in a higher reaction force of the primary cutting edges of the drill bit.

Afterwards, the primary cutting edges played the most important role to completely perforate the laminate, and the thrust force became relatively stable across stage $\mathrm{C}$. Similarly, based on the analysis for the phase B, the experimentally measured thrust force of the toughened laminates was higher again due to the predominance of the primary cutting edges.

In addition, the comparison of thrust forces in Fig. 10 could help to validate the previous assessment in section 4.1 that the toughening effect was maximised for a relatively intensive feed rate condition. In Fig. 10c, the greatest errors at both stages B and C between toughened and untoughened laminates could be always obtained, which indicated a better resistance to the primary cutting edges when the drill bit tent to perforate the laminate.

\subsubsection{Torque}

The torque-time histories for comparison of untoughened and toughened with $10 \mathrm{wt} . \%$ of PMMA laminates were experimentally measured in Fig. 12, at different feed rate conditions. The torque-time histories were still analysed based on the three phases defined by A, B and C. For stages A and B, it can be seen that a greater torque was always shown for toughened laminates, however, for stage $\mathrm{C}$, it was reverse that the 
torque value of toughened laminates became smaller than those without toughening. Following the analysis in 4.2.1, due to the higher bending resistance of the toughened laminates, there was a larger contact area between the top surface of laminate and drill bit, and therefore resulting in a higher torque. However, for the untoughened laminate, the thrust force predominantly contributed the deformation of laminate through the thickness, which the torque effect was thus weakened. Once the drill bit penetrated the laminates, the improved toughening behaviour by PMMA was more obvious to resist the form and propagation of delaminations and prevent the further penetration, therefore a higher torque was required to overcome it. That is why the higher torque was always observed for the toughened laminates until stage B.

When it came to the stage $C$, the torque value of toughened laminate drilled under feed rate of $150 \mathrm{~mm} / \mathrm{min}$ was remarkably lower than that of untoughened laminate. That might be due to the untoughened laminate was more bent than toughened one and at the exit of the hole the drill bit had to cut off the excessive deformed material and therefore required a stronger torque.

It can be also seen that when the feed rates were higher, for instance, $550 \mathrm{~mm} / \mathrm{min}$, there was only a slight difference of torque between toughened and untoughened laminates at this stage. This phenomenon could be due to the thrust load has primarily contributed the perforation at such intensive feed rate. At the exit of the hole, consequently, there were more damages formed instead of the deformation due to bending by the feed rate of $150 \mathrm{~mm} / \mathrm{min}$. Therefore, for either type of laminate, a far difference of torque was rarely found. This hypothesis could be further validated by the previous damage assessment images at the exit of hole, in Table 6.

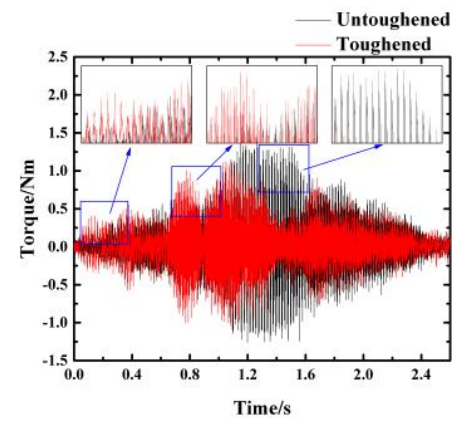

(a) $150 \mathrm{~mm} / \mathrm{min}$

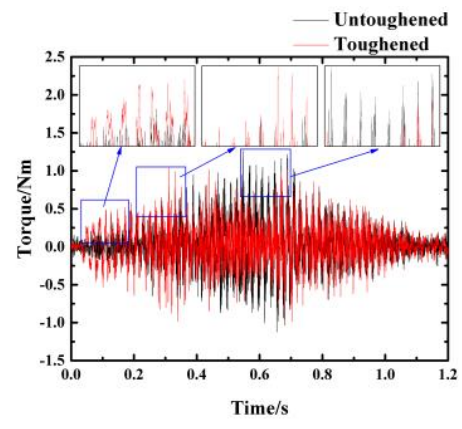

(b) $350 \mathrm{~mm} / \mathrm{min}$

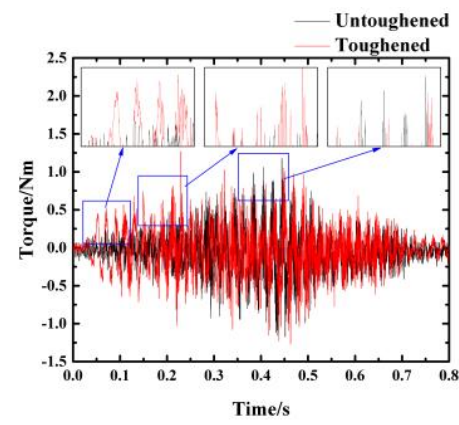

(c) $550 \mathrm{~mm} / \mathrm{min}$

Fig. 12 Torque induced in the drilling of CFRPs untoughened or toughened by $10 \mathrm{wt}$ \% concentration PMMA under different feed rate

\section{Conclusion}

In this paper, a novel approach by inkjet printing the micro-scaled toughener was developed to study the delamination resistance for the composite drilling. PMMA was printed onto the prepregs to improve the interlaminar fracture toughness of the 
CFRP laminates. The effects of toughener weight contents and feed rates were experimentally measured to assess the induced delamination resistance through drilling. The delamination images were discussed combing with the predicted damage areas and factors. To further figure out the mechanisms of the toughening effect on drilling process, the thrust forces and torques were analysed in details, respectively, which the $10 \mathrm{wt} . \%$ of toughening content was selected as a typical example to be compared with untoughened laminates under the various feed rates. Some key conclusions can be drawn as follows:

1. In general, the delamination induced at the hole exit was increased with an increasing of the feed rate, however, due to the toughening effect, both damage areas and damage index factor were significantly reduced. The less damages were visually found by the damage images captured.

2. The optimal content of the PMMA toughener was suggested to be $10 \mathrm{wt}$. \%, which was more obvious for the relatively high feed rate. For the low feed rate condition $(\leq 150 \mathrm{~mm} / \mathrm{min})$ a content of $5 \mathrm{wt} . \%$ was advised to use by considering the fabrication efficiency.

3. The printed tougheners have affected both thrust force and torque during drilling. This was because the toughened laminates generally exhibited a better bending resistance and therefore there were less damages produced at the exit of the hole once the drilling was completed, which was particularly obvious to the relatively higher feed rate operation.

This study is helpful to find out how the additive inkjet printing technology helped to toughen the whole laminate with improvement of damage resistance during drilling. It will be aimed to offer a useful guidance on optimisation of composite drilling, especially suitable to the cases which request high feed rate processing, for both enhanced drilling quality and efficiency.

\section{Acknowledgement}

This work acknowledges the support of facilities for the inkjet printing and manufacturing of composite in Chester Smart Composite Group, University of Chester. It is financially supported by the National Key R\&D Program of China (Grant No. 2018YFA0702803), the National Natural Science Foundation of China United with Liaoning Province (Grant No. U1508207), the National Natural Science Foundation of China (Grant No. 51575082), the National Innovative Research Group (Grant No. 51621064), and the State Scholarship Fund of China offered by China Scholarship Council (CSC).

\section{References}

[1] Che D, Saxena I, Han P, Guo P, Ehmann KF. Machining of carbon fiber reinforced 
plastics/polymers: A literature review. Journal of Manufacturing Science and Engineering, Transactions of the ASME 2014;136.

[2] Abrão AM, Faria PE, Rubio JCC, Reis P, Davim JP. Drilling of fiber reinforced plastics: A review. JOURNAL OF MATERIALS PROCESSING TECHNOLOGY 2007;186:1-7.

[3] Khashaba UA. Drilling of polymer matrix composites: A review. JOURNAL OF COMPOSITE MATERIALS 2012;47:1817-32.

[4] Dandekar CR, Shin YC. Modeling of machining of composite materials: A review. International Journal of Machine Tools and Manufacture 2012;57:102-21.

[5] Wang H, Ning F, Hu Y, Cong W. Surface grinding of CFRP composites using rotary ultrasonic machining: a comparison of workpiece machining orientations. The International Journal of Advanced Manufacturing Technology 2018;95:2917-30.

[6] El-Sonbaty I, Khashaba UA, Machaly T. Factors affecting the machinability of GFR/epoxy composites. COMPOSITE STRUCTURES 2004;63:329-38.

[7] Faraz A, Biermann D, Weinert K. Cutting edge rounding: An innovative tool wear criterion in drilling CFRP composite laminates. International Journal of Machine Tools and Manufacture 2009;49:1185-96.

[8] Tan CL, Azmi AI, Azmi AI, Muhammad N. Delamination and Surface Roughness Analyses in Drilling Hybrid Carbon/Glass Composite. MATERIALS AND MANUFACTURING PROCESSES 2016;31:1366-76.

[9] Ning F, Cong W, Wang H, Hu Y, Hu Z, Pei Z. Surface grinding of CFRP composites with rotary ultrasonic machining: a mechanistic model on cutting force in the feed direction. The International Journal of Advanced Manufacturing Technology 2017;92:1217-29.

[10] Wang C, Ming W, An Q, Chen M. Machinability characteristics evolution of CFRP in a continuum of fiber orientation angles. MATERIALS AND MANUFACTURING PROCESSES 2017;32:104150 .

[11] Wang F, Qian B, Jia Z, Fu R, Cheng D. Secondary cutting edge wear of one-shot drill bit in drilling CFRP and its impact on hole quality. COMPOSITE STRUCTURES 2017;178:341-52.

[12] Shi Y, Soutis C. Modelling transverse matrix cracking and splitting of cross-ply composite laminates under four point bending. THEORETICAL AND APPLIED FRACTURE MECHANICS 2016;83:73-81.

[13] Wang F, Qian B, Jia Z, Cheng D, Fu R. Effects of cooling position on tool wear reduction of secondary cutting edge corner of one-shot drill bit in drilling CFRP. The International Journal of Advanced Manufacturing Technology 2018;94:4277-87.

[14] Shi Y, Pinna C, Soutis C. Modelling impact damage in composite laminates: A simulation of intraand inter-laminar cracking. COMPOSITE STRUCTURES 2014;114:10-9.

[15] Hocheng H, Tsao CC. The path towards delamination-free drilling of composite materials. JOURNAL OF MATERIALS PROCESSING TECHNOLOGY 2005;167:251-64.

[16] Tsao CC, Hocheng H. Taguchi analysis of delamination associated with various drill bits in drilling of composite material. International Journal of Machine Tools and Manufacture 2004;44:1085-90.

[17] Hocheng H, Tsao CC. Effects of special drill bits on drilling-induced delamination of composite materials. International Journal of Machine Tools and Manufacture 2006;46:1403-16.

[18] Isbilir O, Ghassemieh E. Finite Element Analysis of Drilling of Carbon Fibre Reinforced Composites. APPLIED COMPOSITE MATERIALS 2012;19:637-56.

[19] Isbilir O, Ghassemieh E. Numerical investigation of the effects of drill geometry on drilling induced 
delamination of carbon fiber reinforced composites. COMPOSITE STRUCTURES 2013;105:12633.

[20] Jia Z, Fu R, Niu B, Qian B, Bai Y, Wang F. Novel drill structure for damage reduction in drilling CFRP composites. International Journal of Machine Tools and Manufacture 2016;110:55-65.

[21] Marques AT, Durão LM, Magalhães AG, Silva JF, Tavares JMRS. Delamination analysis of carbon fibre reinforced laminates: Evaluation of a special step drill. COMPOSITES SCIENCE AND TECHNOLOGY 2009;69:2376-82.

[22] Durão LMP, Gonçalves DJS, Tavares JMRS, de Albuquerque VHC, Aguiar Vieira A, Torres Marques A. Drilling tool geometry evaluation for reinforced composite laminates. COMPOSITE STRUCTURES 2010;92:1545-50.

[23] Davim JP, Reis P. Drilling carbon fiber reinforced plastics manufactured by autoclave experimental and statistical study. MATERIALS \& DESIGN 2003;24:315-24.

[24] Tsao CC. Evaluation of the drilling-induced delamination of compound core-special drills using response surface methodology based on the Taguchi method. The International Journal of Advanced Manufacturing Technology 2012;62:241-7.

[25] Feito N, Diaz-Álvarez J, López-Puente J, Miguelez MH. Numerical analysis of the influence of tool wear and special cutting geometry when drilling woven CFRPs. COMPOSITE STRUCTURES 2016;138:285-94.

[26] Shahrajabian H, Farahnakian M. Modeling and multi-constrained optimization in drilling process of carbon fiber reinforced epoxy composite. International Journal of Precision Engineering and Manufacturing 2013;14:1829-37.

[27] Odagiri N, Kishi H, Yamashita M. Development of TORAYCA prepreg P2302 carbon fiber reinforced plastic for aircraft primary structural materials. ADVANCED COMPOSITE MATERIALS 1996;5:249-54.

[28] Matsuda S, Hojo M, Ochiai S. Mesoscopic fracture mechanism of mode II delamination fatigue crack propagation in interlayer-toughened CFRP. JSME INTERNATIONAL JOURNAL SERIES A-SOLID MECHANICS AND MATERIAL ENGINEERING 1997;40:423-9.

[29] Hojo M, Matsuda S, Tanaka M, Ochiai S, Murakami A. Mode I delamination fatigue properties of interlayer-toughened CF/epoxy laminates. COMPOSITES SCIENCE AND TECHNOLOGY 2006;66:665-75.

[30] Sato N, Hojo M, Nishikawa M. Intralaminar fatigue crack growth properties of conventional and interlayer toughened CFRP laminate under mode I loading. Composites Part A: Applied Science and Manufacturing 2015;68:202-11.

[31] Wang WX, Takao Y, Matsubara T, Kim HS. Improvement of the interlaminar fracture toughness of composite laminates by whisker reinforced interlamination. 2002;62:767-74.

[32] Arai M, Noro Y, Sugimoto K, Endo M. Mode I and mode II interlaminar fracture toughness of CFRP laminates toughened by carbon nanofiber interlayer. COMPOSITES SCIENCE AND TECHNOLOGY 2008;68:516-25.

[33] Hamer S, Leibovich H, Green A, Intrater R, Avrahami R, Zussman E, et al. Mode I interlaminar fracture toughness of Nylon 66 nanofibrilmat interleaved carbon/epoxy laminates. POLYMER COMPOSITES 2011;32:1781-9.

[34] Magniez K, Chaffraix T, Fox B. Toughening of a Carbon-Fibre Composite Using Electrospun Poly(Hydroxyether of Bisphenol A) Nanofibrous Membranes Through Inverse Phase Separation and Inter-Domain Etherification. Materials 2011;4:1967-84. 
[35] Liu D, Li G, Li B, Yang X. Establishment of multi-scale interface in interlayer-toughened CFRP composites by self-assembled PA-MWNTs-EP. COMPOSITES SCIENCE AND TECHNOLOGY 2016;130:53-62.

[36] White KL, Sue H. Delamination toughness of fiber-reinforced composites containing a carbon nanotube/polyamide-12 epoxy thin film interlayer. POLYMER 2012;53:37-42.

[37] Ho-Cheng H, Dharan C. Delamination during drilling in composite laminates. 1990.

[38] Sato N, Hojo M, Nishikawa M. Novel test method for accurate characterization of intralaminar fracture toughness in CFRP laminates. Composites Part B: Engineering 2014;65:89-98.

[39] EC-TDS-XC130-Prepreg.

[40] Yi Zhang PhD Thesis.

[41] Isbilir O, Ghassemieh E. Delamination and wear in drilling of carbon-fiber reinforced plastic composites using multilayer TiAIN/TiN PVD-coated tungsten carbide tools. JOURNAL OF REINFORCED PLASTICS AND COMPOSITES 2012;31:717-27.

[42] Phadnis VA, Makhdum F, Roy A, Silberschmidt VV. Drilling in carbon/epoxy composites: Experimental investigations and finite element implementation. Composites Part A: Applied Science and Manufacturing 2013;47:41-51.

[43] Babu J, Sunny T, Paul NA, Mohan KP, Philip J, Davim JP. Assessment of delamination in composite materials: A review. Proceedings of the Institution of Mechanical Engineers, Part B: Journal of Engineering Manufacture 2016;230:1990-2003. 